\title{
Influence of age and geographical origin in the prevalence of high risk human papillomavirus in migrant female sex workers in Spain
}

\author{
J del Amo, C González, J Losana, P Clavo, L Muñoz, J Ballesteros, A García-Saiz, M J Belza, \\ M Ortiz, B Menéndez, J del Romero, F Bolumar
}

Sex Transm Infect 2005;81:79-84. doi: 10.1136/sti.2003.008060

See end of article for authors' affiliations

.....................

Correspondence to: Julia del Amo,

Departamento de Salud Publica, Universidad Miguel Hernandez, Campus de San Juan, Crtra Alicante-Valencia Km.87, 03550 San Juan-Alicante, Spain; jamo@umh.es

Accepted for publication 5 February 2004

\begin{abstract}
Objectives: To estimate the prevalence and risk factors of high risk human papillomavirus (HPV) infection in migrant female sex workers (FSW) according to age and geographical origin.

Methods: Cross sectional study of migrant FSW attending a sexually transmitted infection (STI) clinic in Madrid during 2002. Information on sociodemographic characteristics, reproductive and sexual health, smoking, time in commercial sex work, history of STIs, HIV, hepatitis B, hepatitis C, syphilis, and genitourinary infections was collected. High risk HPV Infection was determined through the Digene HPV Test, Hybrid Capture II. Data were analysed through multiple logistic regression.

Results: 734 women were studied. Overall HPV prevalence was 39\%; 61\% in eastern Europeans, 42\% in Ecuadorians, $39 \%$ in Colombians, $29 \%$ in sub-Saharan Africans, and $24 \%$ in Caribbeans ( $p=0.057$ ). HPV prevalence showed a decreasing trend by age; $49 \%$ under 20 years, 35\% in $21-25$ years, $14 \%$ over 36 years\% $(p<0.005)$. In multivariate analyses, area of origin $(p=0.07)$, hormonal contraception in women not using condoms (OR $19.4595 \% \mathrm{Cl}$ : 2.45 to 154.27), smoking, age, and an interaction between these last two variables $(p=0.039)$ had statistically significant associations with HPV prevalence. STI prevalence was $11 \%$ and was not related to age or geographical origin.

Conclusions: High risk HPV prevalence in migrant FSW is elevated and related to age, area of origin, and use of oral contraceptives in women not using condoms. These data support the role of acquired immunity in the epidemiology of HPV infection and identifies migrant FSW as a priority group for sexual health promotion.
\end{abstract}

$\mathrm{H}$ uman papillomavirus infection (HPV) is the commonest sexually transmitted infection (STI) worldwide. More than 20 types of papillomavirus have been associated with cervical cancer, the second cause of cancer related mortality in women globally. ${ }^{1-3}$ Most HPV infections are asymptomatic and resolve spontaneously with cervical smear abnormalities only occurring in those women with persistent HPV infection. ${ }^{45}$ The advent of molecular biology tools in HPV diagnosis has allowed us to identify HPV infection, differentiate HPV types, and discriminate groups of the population with different risks of infection. ${ }^{2}$

HPV prevalence depends largely on age and on sexual practices. ${ }^{6-8}$ The prevalence of high risk HPV ranges from $11 \%$ in healthy women in Belgium, ${ }^{9}$ 20\% in female university students in the United States ${ }^{10}$ to $36 \%$ in Italian women at risk for human immunodeficiency virus (HIV) infection ${ }^{11}$ and $46 \%$ in Spanish women in prisons. ${ }^{12}$ The highest prevalences of HPV have been described in female sex workers (FSWs) as they have multiple risk factors for HPV infection, such as young age and multiple sexual contacts. ${ }^{13-16}$ There is wide heterogeneity in reported HPV prevalences in FSW from studies in different geographical areas; $43 \%$ in Mexico, ${ }^{14} 48 \%$ in Japan, ${ }^{15}$ and $63 \%$ in Calcutta, India. ${ }^{16}$

Over the last few years, an increasing proportion of the FSWs in European countries are migrants. ${ }^{17}$ This phenomenon has also occurred in Spain, where a very large proportion of these women originate from other countries, the majority from South America. ${ }^{18-20}$ It is likely that migrant FSWs differ from other groups of the population in terms of sociodemographic characteristics, sexual and health seeking behaviour, as well as HPV prevalence and types. The knowledge of these characteristics is essential to design appropriate preventive and curative strategies.

The objective of this work is to estimate the prevalence of high risk HPV infection in migrant FSW attending the largest STI clinic in Madrid during 2002 according to their age and geographical origin, and identify risk factors associated with it.

\section{SUBJECTS AND METHODS}

Cross sectional study of all migrant female sex workers who attended "Centro Sanitario Sandoval," the largest STI clinic in Madrid, from January to September 2002. The Centro Sanitario Sandoval is an ambulatory STI clinic and HIV screening centre whose access is open, free, and anonymous and which has been a pioneering centre in STDs and HIV prevention in Spain. Information on sociodemographic characteristics (age, country of birth, marital status) reproductive health (number of pregnancies, children, termination of pregnancies (TOP), type of contraceptives (hormonal or not) and barriers methods used, smoking habits, time in commercial sex work, reasons for attending the clinic, past history of STI and/or genitourinary infections (GUI) was collected. Full gynaecological examinations were conducted and all women had cervical and vaginal swabs and vaginal fresh specimens to test for STIs (gonorrhoea, Chlamydia trachomatis, Trichomonas vaginalis) and/or other genitourinary

Abbreviations: FSW female sex workers, ; HC, hormonal contraception; HPV, human papillomavirus; IUD, intrauterine device; TL, tubal ligation; TOP, termination of pregnancy 
infections (bacterial vaginosis and vaginal candidiasis). Serological tests for hepatitis B infection (HBsAg, HBcAb), hepatitis C (HCV), and syphilis (RPR, TPHA) were also carried out. HIV test with informed consent was requested.

High risk HPV infection was determined through Digene HPV Test, Hybrid Capture II which identified types 16, 18, 31, $33,35,39,45,51,52,56,58,59$, and 68 . All cervical swabs were taken and placed in a tube containing Digene specimen transport medium $(1 \mathrm{ml})$ and stored at $-20^{\circ} \mathrm{C}$ until required for testing. HC2 HPV DNA test was performed in all samples using the high risk HPV probe mixture only, to minimise cost of testing. The exfoliated cells are first treated with alkali denaturing reagent and the processed samples are hybridised under high stringency conditions. Positive specimens are detected by binding the hybridisation complexes onto the surface of microplate well coated with monoclonal antibodies specific to RNA-DNA hybrids. Immobilised hybrids are detected by the addition of an alkaline phosphatase conjugated antibody to RNA-DNA hybrids, followed by the addition of a chemiluminescent substrate.

\section{Statistical analyses}

Data analysis was performed on microcomputer using Stata vs 6 software. The univariate analysis of demographic and clinical differences were analysed using the two sample $t$ test for normally distributed continuous data, the Mann-Whitney test for non-parametric data, the $\chi^{2}$ test for frequencies, and Fisher's test and the $\chi^{2}$ test for trend. Multiple logistic regression modelling was used for the analysis of associations between variables where some were considered possible confounders after checking for interactions.

\section{RESULTS}

Sociodemographic characteristics

In all, 734 women were included in the study; 397 (54\%) originated from Colombia, $158(22 \%)$ from Ecuador, 70 (10\%) from the Caribbean, 25 (3\%) from other Latin American countries, $24(3 \%)$ from sub-Saharan Africa, 18 $(2 \%)$ from eastern Europe, and $42(6 \%)$ from other countries (table 1). Median age was 27 years (range 16-50) with variations seen according to country of origin; the youngest women were from eastern Europe whose median age was 22 years (table 1$)$.

Most women were single and this pattern was similar across all countries of origin. Over half of these women, 395 (54\%), had one or more children though marked differences were seen according to areas of origin; while this proportion was around $50 \%$ for Latin American countries, it was below $25 \%$ for FSW originating from eastern Europe and subSaharan Africa. Of those women with data on terminations of pregnancies (TOPs), 274 (38\%) had had at least one TOP in their lifetime; $33 \%$ of the Colombians, $43 \%$ of the Ecuadorians, $28 \%$ of the eastern Europeans, and $51 \%$ of the Caribbeans (table 1). A high proportion of the women used condoms as contraceptive methods, either alone $(60 \%$ of the women) or in combination with hormonal contraceptives $(27 \%)$ or with mechanical methods $(9 \%)$ (table 1 ).

Median time of sex work was 0.7 years although this information was only available in $60 \%$ of the women (table 1). The women from the Caribbean and sub-Saharan Africa had been working in commercial sex for longer periods of time (median times of 1 year respectively) compared to women from Colombia and eastern Europe (median times of

Table 1 Sociodemographic and reproductive characteristics of migrant FSWs according to geographical origin

\begin{tabular}{|c|c|c|c|c|c|c|c|c|}
\hline \multirow[b]{3}{*}{ Variables } & \multirow{2}{*}{$\begin{array}{l}\text { Total } \\
\text { No (\%) }\end{array}$} & \multirow{2}{*}{$\begin{array}{l}\text { Colombia } \\
\text { No }(\%)\end{array}$} & \multirow{2}{*}{$\begin{array}{l}\text { Ecuador } \\
\text { No }(\%)\end{array}$} & \multirow{2}{*}{$\begin{array}{l}\text { Caribbean } \\
\text { No (\%) }\end{array}$} & \multirow{2}{*}{$\begin{array}{l}\text { Latin America } \\
\text { No (\%) }\end{array}$} & \multirow{2}{*}{$\begin{array}{l}\text { Sub-Saharan } \\
\text { Africa } \\
\text { No (\%) }\end{array}$} & \multirow{2}{*}{$\begin{array}{l}\text { Eastern } \\
\text { Europe } \\
\text { No (\%) }\end{array}$} & \multirow{2}{*}{$\begin{array}{l}\text { Others } \\
\text { No (\%) }\end{array}$} \\
\hline & & & & & & & & \\
\hline & $734(100)$ & $397(54)$ & $158(22)$ & 70 (10) & $25(3)$ & $24(3)$ & $18(2)$ & $42(6)$ \\
\hline \multicolumn{9}{|l|}{ Age (years) } \\
\hline$<20$ & $83(11)$ & $45(11)$ & 20 (13) & $6(9)$ & $1(4)$ & $2(8)$ & $4(22)$ & $5(12)$ \\
\hline $21-25$ & $214(29)$ & $106(27)$ & 49 (31) & $23(33)$ & $9(36)$ & $10(42)$ & $9(50)$ & $8(19)$ \\
\hline $26-30$ & $180(25)$ & $102(26)$ & $41(26)$ & 12 (17) & $6(24)$ & $5(21)$ & $4(22)$ & $10(24)$ \\
\hline $31-35$ & $180(25)$ & $100(25)$ & $38(24)$ & 19 (27) & $4(16)$ & $6(25)$ & $1(6)$ & $12(28)$ \\
\hline$>36$ & $76(10)$ & $43(11)$ & $10(6)$ & 10 (14) & $5(20)$ & $1(4)$ & $0(0)$ & $7(17)$ \\
\hline \multicolumn{9}{|l|}{ No of children } \\
\hline 0 & $339(46)$ & $177(45)$ & $60(38)$ & $35(50)$ & $12(48)$ & $18(75)$ & $16(89)$ & $21(50)$ \\
\hline 1 & $215(29)$ & 119 (30) & 50 (32) & $18(26)$ & $8(32)$ & $5(21)$ & $2(11)$ & $13(31)$ \\
\hline$>1$ & $180(25)$ & $101(25)$ & $48(30)$ & $17(24)$ & $5(20)$ & $1(4)$ & $0(0)$ & $8(19)$ \\
\hline \multicolumn{9}{|l|}{ No of TOPs } \\
\hline 0 & $312(42)$ & $194(49)$ & 61 (39) & $23(33)$ & $9(36)$ & $4(17)$ & $6(33)$ & $15(36)$ \\
\hline 1 & $182(25)$ & $98(25)$ & 45 (28) & $20(28)$ & $5(20)$ & $3(12)$ & $3(17)$ & $8(19)$ \\
\hline$>1$ & $92(13)$ & $33(8)$ & 23 (15) & $16(23)$ & $5(20)$ & $4(17)$ & $2(11)$ & $9(21)$ \\
\hline Unknown & $148(20)$ & 72 (18) & 29 (18) & 11 (16) & $6(24)$ & $13(54)$ & $7(39)$ & $10(24)$ \\
\hline \multicolumn{9}{|c|}{ Contraceptive method } \\
\hline Condoms only & $439(60)$ & $214(54)$ & $97(61)$ & $51(73)$ & $17(68)$ & 19 (79) & $15(83)$ & $26(62)$ \\
\hline $\mathrm{HC}$ only & $15(2)$ & $11(3)$ & $3(2)$ & 0 & 0 & 0 & $1(6)$ & 0 \\
\hline Condoms + HC & $199(27)$ & $114(29)$ & $41(26)$ & $17(24)$ & $6(24)$ & $5(21)$ & $2(11)$ & $14(33)$ \\
\hline Condoms + IUD/TL & $69(9)$ & $48(12)$ & $15(10)$ & $2(3)$ & $2(8)$ & 0 & 0 & $2(5)$ \\
\hline IUD/TL & $12(2)$ & $10(2)$ & $2(1)$ & 0 & 0 & 0 & 0 & 0 \\
\hline $\begin{array}{l}\text { Median years sex } \\
\text { work } \\
\text { Smoking }\end{array}$ & 0.7 & 0.6 & 0.7 & 1 & 1 & 1 & 0.6 & 1 \\
\hline Yes & $156(21)$ & $82(21)$ & $32(20)$ & $11(16)$ & $5(20)$ & $2(8)$ & $8(44)$ & $16(38)$ \\
\hline No & $317(43)$ & $181(45)$ & 78 (49) & $32(46)$ & $8(32)$ & $5(21)$ & $1(6)$ & $12(29)$ \\
\hline Unknown & $261(36)$ & $134(34)$ & $48(31)$ & $27(38)$ & $12(48)$ & $17(71)$ & $9(50)$ & $14(33)$ \\
\hline \multicolumn{9}{|l|}{ Consultation } \\
\hline Acute symptoms & 435 (59) & $232(58)$ & $99(63)$ & $46(66)$ & $15(60)$ & $14(58)$ & $9(50)$ & $20(48)$ \\
\hline Routine control & 270 (37) & $150(38)$ & 51 (32) & $22(31)$ & $9(36)$ & 7 (29) & $9(50)$ & $22(52)$ \\
\hline $\begin{array}{l}\text { HIV test/condom } \\
\text { break }\end{array}$ & $29(4)$ & $15(4)$ & $8(5)$ & $2(3)$ & $1(4)$ & $3(13)$ & $0(0)$ & $0(0)$ \\
\hline
\end{tabular}


Table 2 Prevalence of current STIs and genitourinary infections in migrant FSWs according to geographical origin

\begin{tabular}{|c|c|c|c|c|c|c|c|c|}
\hline \multirow[b]{3}{*}{ Variables } & \multirow{2}{*}{$\frac{\text { Total }}{\text { No (\%) }}$} & \multirow{2}{*}{$\frac{\text { Colombia }}{\text { No (\%) }}$} & \multirow{2}{*}{$\frac{\text { Ecuador }}{\text { No (\%) }}$} & \multirow{2}{*}{$\begin{array}{l}\text { Caribbean } \\
\text { No (\%) }\end{array}$} & \multirow{2}{*}{$\frac{\text { Latin America }}{\text { No }(\%)}$} & \multirow{2}{*}{$\begin{array}{l}\text { Sub-Saharan } \\
\text { Africa } \\
\text { No (\%) }\end{array}$} & \multirow{2}{*}{$\begin{array}{l}\text { Eastern } \\
\text { Europe } \\
\text { No (\%) }\end{array}$} & \multirow{2}{*}{$\frac{\text { Others }}{\text { No (\%) }}$} \\
\hline & & & & & & & & \\
\hline & $734(100)$ & $397(54)$ & 158 (22) & $70(10)$ & $25(3)$ & $24(3)$ & $18(2)$ & $42(6)$ \\
\hline Current acute STI* & $84(11)$ & 46 (12) & $19(12)$ & $10(14)$ & $0(0)$ & $4(17)$ & $2(11)$ & $3(7)$ \\
\hline High risk HPV & $283(39)$ & $156(39)$ & $67(42)$ & $17(24)$ & $9(36)$ & $7(29)$ & 11 (61) & $16(38)$ \\
\hline Bacterial vaginosis & 195 (27) & $99(25)$ & $43(27)$ & $16(23)$ & $5(20)$ & $14(58)$ & $3(17)$ & $15(36)$ \\
\hline Candida albicans & $196(27)$ & 95 (24) & $45(28)$ & $20(29)$ & $9(36)$ & $11(46)$ & $6(33)$ & $10(24)$ \\
\hline RPR & 30 (4) & $17(4)$ & $4(3)$ & $3(4)$ & $3(12)$ & 1 (4) & $1(6)$ & $1(2)$ \\
\hline TPHA & $82(11)$ & $40(10)$ & $23(15)$ & $9(13)$ & $1(4)$ & $2(8)$ & $2(11)$ & $5(12)$ \\
\hline $\mathrm{HbcAc}$ & $57(8)$ & $19(5)$ & $6(4)$ & $14(20)$ & $1(4)$ & $8(33)$ & $5(28)$ & $4(9)$ \\
\hline $\mathrm{HbsAg}$ & $2(0.3)$ & $1(0.2)$ & $0(0)$ & $1(1)$ & $0(0)$ & $0(0)$ & $0(0)$ & $0(0)$ \\
\hline $\mathrm{HCV}$ & $1(0,1)$ & $1(0,2)$ & $0(0)$ & $0(0)$ & $0(0)$ & $0(0)$ & $0(0)$ & $0(0)$ \\
\hline HIV & $5(0.7)$ & $2(0.5)$ & $0(0)$ & $0(0)$ & $0(0)$ & $2(8)$ & $0(0)$ & $1(2)$ \\
\hline
\end{tabular}

0.6 year respectively. Data on smoking were only available in $64 \%$ of the women of whom $156(39 \%)$ did smoke (table 1).

A high proportion of women, 435 (59\%), attended the STI clinic because of acute symptoms and 270 (37\%) went for routine check ups (table 1 ). There were no marked differences in the reasons for visiting the clinic according to the area of origin.

\section{Prevalence of HPV and other infections}

Forty five women $(6 \%)$ had a past self reported history of an STI, with differences according to the area of origin; $7 \%$ of the Colombians, $8 \%$ of the sub-Saharan Africans, none of the eastern Europeans and 13\% of the Caribbeans. A higher number of women, $182(25 \%)$, reported a past history of genitourinary infections; $25 \%$ of the Colombians, $25 \%$ of the sub-Saharan Africans, $27 \%$ of the eastern Europeans, and $37 \%$ of the Caribbeans.

Current STI prevalence was $11 \%$ and there were no statistically significant differences by geographical origin (table 2). Overall high risk HPV prevalence was 39\%, with differences according to area of origin; the lowest HPV prevalence was seen in FSW from the Caribbean, 24\%, and the highest in FSW from eastern Europe (61\%) (table 2). In spite of small numbers, differences were of borderline statistical significance $(\mathrm{p}=0.065)$.

Five women $(0.7 \%)$ were HIV positive; two of these five women were Colombians and two were sub-Saharan Africans; HIV prevalence for FSW from Colombia was 0.5\% and was $8 \%$ for FSW from Africa. There was only one case of HCV infection in a Colombian woman. Two women were HBsAg positive and $57(8 \%)$ had HBCAb. Prevalence of $\mathrm{HBCAb}$ was higher in women from sub-Saharan Africa (33\%), from eastern Europe (28\%) and the Caribbean (20\%). TPHA was positive in $82(11 \%)$ of the women and RPR in 30 $(4 \%)$ of them with heterogeneous variations according to country of origin (table 2).

\section{Variables associated with the presence of high risk HPV infection and other acute STIs}

In univariate analyses, area of origin, age, marital status, use of hormonal contraceptives in women who did not report using barrier methods, smoking, number of children and number of TOPs had statistically significant associations with HPV infection (table 3 ). Use of hormonal contraceptives in women who also reported using condoms was not associated with an increased risk of HPV infection.

The prevalence of HPV infection was higher in younger women and showed a downward trend with increasing age; for women under 20 years, HPV prevalence was 53\%, 35\% for those between 26 and 30 years, and $14 \%$ for those over
36 years ( $\mathrm{p}$ for trend 0.000 ) (table 3 ). The risk of being infected by HPV was more than double (OR $2.395 \%$ CI: 1.7 to 3.2 ) in women over 25 years compared to under 25 years and this pattern was seen for all areas of origin although the magnitude of the association varied from 1.9 (95\% CI: 1.3 to 2.9) in Colombians and 1.8 (95\% CI: 1 to 3.5) in Ecuadorians to the large and imprecise estimate of 11 (95\% CI:1.1 to 114.1) in sub-Saharan Africans and 13.3 (95\% CI:1 to 169.6) in eastern Europeans.

Most of the variables identified as predictive of HPV infection in univariate analyses were confounded by age since multivariate analyses revealed that only age, area of origin, smoking, hormonal contraception in women who did not report using condoms, and the interaction between age and smoking were statistically associated with HPV infection (LR test for the interaction p 0.039). Risk of HPV infection was lower in smokers over 25 years (OR 0.33 95\% CI: 0.17 to 0.63 ) compared to non-smokers over 25 years (baseline) but was higher in women under 25, smokers, non-smokers, and those with unknown smoking status (table 4). Hormonal contraception in women not using barrier methods was associated with an increased risk of HPV infection (OR 19.45 95\% CI: 2.45 to 154.27 ) (table 4 ).

The variables identified as predictive of HPV infection were not associated with the presence of an acute STI (table 3 ). There were no significant differences by geographical origin; only women from sub-Saharan Africa had a non-statistically significant higher proportion of STIs (17\%) compared to the mean ( $11 \%)$. Although women under 20 years had a slightly higher prevalence of STIs (16\%), no trend was seen and differences were not statistically significant (table 3 ). The only variables which were associated with a higher risk of an acute STI univariately were having more than one child and having a concurrent genitourinary infection. A positive syphilis serology was also associated with a double risk of having an acute STI although differences were of borderline statistical significance (table 3 ). Multivariate analyses did not modify the results observed in univariate analyses (data not shown).

\section{DISCUSSION}

This study has found an high prevalence of HPV infection in migrant FSWs attending a large STI clinic in Madrid which was associated with age and geographical origin. The highest prevalence was observed in women under 20 years old, of whom half were infected, and a decreasing prevalence with age was observed. FSW from sub-Saharan Africa and the Caribbean had the lowest risks of HPV infection in univariate and multivariate analyses and women from eastern Europe had the highest risk, although differences were of borderline 
Table 3 Univariate analyses and prevalence of HPV infection and acute STIs in migrant FSWs

\begin{tabular}{|c|c|c|c|c|c|c|}
\hline Variables & HPV prevalence & OR $(95 \% \mathrm{Cl})$ & p Value & STI prevalence* & OR $(95 \% \mathrm{Cl})$ & p Value \\
\hline \multicolumn{7}{|l|}{ Area of origin } \\
\hline Colombia & $39 \%$ & 1.00 & 0.057 & $12 \%$ & 1.00 & 0.860 \\
\hline Ecuador & $42 \%$ & $1.13(0.78$ to 1.65$)$ & & $12 \%$ & 1.04 (0.59 to 1.84$)$ & \\
\hline Sub-Saharan Africa & $29 \%$ & $0.64(0.26$ to 1.57$)$ & & $17 \%$ & $1.52(0.49$ to 4.66$)$ & \\
\hline Eastern Europe & $61 \%$ & $2.4(0.92$ to 6.39$)$ & & $11 \%$ & $0.95(0.21$ to 4.28$)$ & \\
\hline Caribbean & $24 \%$ & $0.5(0.27$ to 0.88$)$ & & $14 \%$ & $1.27(0.61$ to 2.65$)$ & \\
\hline Latin America (others) & $36 \%$ & 0.86 (0.37 to 2.01$)$ & & - & - & \\
\hline & $38 \%$ & $0.95(0.48$ to 1.83$)$ & & $7 \%$ & $0.58(0.17$ to 1.97$)$ & \\
\hline \multicolumn{2}{|l|}{ Age (years) } & 1.00 & 0.000 & $16 \%$ & 1.00 & \\
\hline $21-25$ & $49 \%$ & 0.87 (0.52 to 1.45 ) & 0.000 & $\begin{array}{l}10 \% \\
12 \%\end{array}$ & 0.71 (0.34 to 1.47 ) & $0.3 / 1$ \\
\hline $26-30$ & $35 \%$ & $0.48(0.28$ to 0.81$)$ & & $8 \%$ & 0.49 (0.22 to 1.08$)$ & \\
\hline $31-35$ & $33 \%$ & $0.43(0.25$ to 0.73$)$ & & $13 \%$ & $0.83(0.39$ to 1.72$)$ & \\
\hline$>36$ & $14 \%$ & $0.15(0.07-0.32)$ & & $9 \%$ & $0.54(0.20$ to 1.45$)$ & \\
\hline \multicolumn{7}{|l|}{ Marital status } \\
\hline Single & $43 \%$ & 1.00 & 0.035 & $12 \%$ & 1.00 & 0.950 \\
\hline Married & $31 \%$ & 0.61 (0.34 to 1.06$)$ & & $13 \%$ & $1.07(0.48$ to 2.38$)$ & \\
\hline Widow/separated & $36 \%$ & $0.74(0.41$ to 1.32$)$ & & $9 \%$ & $0.78(0.29$ to 2.05$)$ & \\
\hline Unknown & $32 \%$ & $0.62(0.42$ to 0.89$)$ & & $11 \%$ & 0.93 (0.54 to 1.62$)$ & \\
\hline \multicolumn{7}{|l|}{ No of children } \\
\hline 0 & $44 \%$ & 1.00 & 0.005 & $12 \%$ & 1.00 & 0.021 \\
\hline 1 & $37 \%$ & 0.73 & & $7 \%$ & 0.54 (0.29 to 1.01$)$ & \\
\hline$>1$ & $30 \%$ & 0.54 & & $16 \%$ & 1.34 (0.79 to 2.24$)$ & \\
\hline \multicolumn{7}{|l|}{ No of TOPS } \\
\hline 0 & $40 \%$ & 1.00 & 0.004 & $13 \%$ & 1.00 & 0.663 \\
\hline 1 & $33 \%$ & 0.74 & & $9 \%$ & $0.66(0.36$ to 1.20 & \\
\hline$>1$ & $27 \%$ & 0.54 & & $10 \%$ & 0.67 (0.27 to 1.67$)$ & \\
\hline \multicolumn{7}{|l|}{ Contraceptive method } \\
\hline Condoms only & $39 \%$ & 1.00 & 0.000 & $13 \%$ & 1.00 & 0.37 \\
\hline HC only & $93 \%$ & 22 (2.9 to 171.6$)$ & & - & - & \\
\hline Condoms + HC & $36 \%$ & $0.9(0.6$ to 1.2$)$ & & $10 \%$ & $0.73(0.43$ to 1.26$)$ & \\
\hline Condoms + IUD/TL & $35 \%$ & $0.8(0.5$ to 1.4$)$ & & $7 \%$ & $0.52(0.20$ to 1.32$)$ & \\
\hline IUD/TL & $42 \%$ & $1.1(0.3$ to 3.65$)$ & & $8 \%$ & 0.59 (0.08 to 4.72$)$ & \\
\hline \multicolumn{7}{|l|}{ Time in sex work } \\
\hline$\leqslant 1$ years & $38 \%$ & 1.00 & 0.56 & $14 \%$ & 1.00 & 0.196 \\
\hline$>1$ years & $31 \%$ & $0.75(0.46$ to 1.22$)$ & & $8 \%$ & 0.55 (0.25 to 1.22$)$ & \\
\hline Unknown & $42 \%$ & $1.2(0.86$ to 1.62$)$ & & $10 \%$ & $0.71(0.44$ to 1.16$)$ & \\
\hline \multicolumn{7}{|l|}{ Smoking } \\
\hline No & $39 \%$ & 1.00 & 0.020 & $9 \%$ & 1.00 & 0.208 \\
\hline Yes & $29 \%$ & $0.64(0.42$ to 0.97$)$ & & $14 \%$ & 1.63 (0.90 to 2.94$)$ & \\
\hline Unknown & $43 \%$ & $1.15(0.83$ to 1.61$)$ & & $13 \%$ & $1.47(0.85$ to 2.44$)$ & \\
\hline \multicolumn{7}{|l|}{ Reason for consultation } \\
\hline Acute symptoms & $39 \%$ & 1.00 & 0.937 & $11 \%$ & 1.00 & 0.784 \\
\hline Routine control & $38 \%$ & 0.95 (0.69 to 1.29$)$ & & $12 \%$ & 1.15 (0.71 to 1.85$)$ & \\
\hline HIV test/condom broke & $38 \%$ & 0.95 (0.44 to $2-07)$ & & $14 \%$ & $1.32(0.44$ to 3.96$)$ & \\
\hline Concurrent GUI & & & 0.94 & & & \\
\hline No & $38 \%$ & 1.00 & & $6 \%$ & 1.00 & 0.00 \\
\hline Yes & $39 \%$ & 1.01 (0.74 to 1.38$)$ & & $15 \%$ & 2.75 (1.54 to 4.90$)$ & \\
\hline Concurrent STls & & & 0.73 & & & \\
\hline No & $38 \%$ & 1.00 & & - & & \\
\hline Yes & $43 \%$ & 1.22 (0.77 to 1.94$)$ & & & & \\
\hline TPHA & & & 0.53 & & & \\
\hline No & $39 \%$ & 1.00 & & $11 \%$ & 1.00 & 0.10 \\
\hline Yes & $35 \%$ & $0.86(0.53$ to 1.38$)$ & & $17 \%$ & 1.71 (0.92 to 3.20$)$ & \\
\hline RPR & & & 0.07 & & & \\
\hline No & $39 \%$ & 1.00 & & $11 \%$ & 1.00 & 0.16 \\
\hline Yes & $23 \%$ & $0.47(0.20$ to 1.11$)$ & & $20 \%$ & 2.00 (2.79 to 5.96$)$ & \\
\hline
\end{tabular}

TOPs = termination of pregnancy; $\mathrm{HC}=$ hormonal contraception; IUD = intrauterine device; $\mathrm{TL}=$ tubal ligation; GUI = genitourinary infection.

*STI: gonorrhoea, Chlamydia trachomatis, Trichomonas vaginalis.

statistical significance. This study has also identified an increased risk of HPV infection in women who had taken hormonal contraceptives and did not report using barrier methods, and a lower risk of HPV for smokers over 25 years old.

The increased prevalence of HPV infection in younger women and the decreasing trend with age was already reported in the mid-1980 $\mathrm{s}^{21}$ and has been described by many studies since then. ${ }^{13} 142223$ The inverse relation between age and HPV prevalence has been attributed to the development of acquired HPV immunity over time after HPV exposure. ${ }^{13} 22$ In our study, this trend in the age pattern was seen in all groups irrespective of their geographical origin although with variations in its magnitude and precision owing to different sample sizes. However, although age confounded many of the associations identified in univariate analyses (marital status, number of children, etc), multivariate analyses adjusting for age, smoking, and use of hormonal contraception in women not using condoms, still revealed borderline statistically significant differences in HPV prevalence by geographical origin.

The highest HPV prevalence was seen in FSWs from eastern Europe, who were also the youngest, and the lowest prevalences were observed in FSW from sub-Saharan Africa and the Caribbean. Although differences were of borderline statistical significance because of the small number of women in some groups and therefore decreased power, they were maintained in age adjusted analyses. Country of origin must, therefore, be reflecting differences in either past or current sexual behaviours, but unfortunately, no detailed 
Table 4 Multivariate analyses of variables predicting increased risk of HPV infection stratified by age in migrant FSWs

\begin{tabular}{lll}
\hline Variables & OR $(95 \% \mathrm{Cl})$ & p Value \\
\hline Area of origin & 1.00 & 0.07 \\
Colombia & $1.11(0.76$ to 1.65$)$ & \\
Ecuador & $0.52(0.20$ to 1.35$)$ & \\
Sub-Saharan Africa & $1.77(0.63$ to 4.97$)$ & \\
Eastern Europe & $0.47(0.26$ to 0.85$)$ & \\
Caribbean & $0.87(0.37$ to 2.07$)$ & \\
Latin America (others) & $1.17(0.59$ to 2.33$)$ & \\
Others/unknown & & \\
Age (years) and smoking & $1.7(0.94$ to 3.1$)$ & \\
$<25$, smoker & $1.63(1.02$ to 2.59$)$ & \\
$<25$, non-smoker & $2.28(1.36$ to 3.8$)$ & \\
$<25$, unknown* & $0.33(0.17$ to 0.63$)$ & \\
$>25$, smoker & 1.00 & \\
$>25$, non-smoker & $0.93(0.59$ to 1.47$)$ & \\
$>25$, unknown* & $19.45(2.45$ to 154.27$)$ & \\
Hormonal contraception only & 1.00 & \\
Yes & & \\
No & & \\
\hline *Unknown smoking status. & & \\
Variables associated with the presence of acute STls. & \\
\hline
\end{tabular}

data were available for all women. The fact that no differences by geographical origin were observed for acute STIs suggests that past exposure to HPV may be a determinant of current HPV epidemiology, in line with what is known of acquired immunity to HPV. Another explanation could be the different natural history and clearance rates of different HPV types, ${ }^{24}$ in case that they were not homogeneously distributed by country of origin. Further research into the HPV types of this sample is currently being conducted.

There is strong evidence of unsafe sex in these women, as highlighted by the high prevalence of termination of pregnancies (over a third) and other STIs (11\%), and it has been shown that unsafe sex takes place with the regular partner and not with clients. ${ }^{25}$ Prevalence of acute STIs was neither related to age nor geographical origin and although differences did not reach statistically significance, prevalence of other STIs was highest among sub-Saharan FSWs and lowest among eastern Europeans. Time spent in commercial sex work and past history of STIs were not associated with HPV prevalence. These data are, nevertheless, sensitive; information on time spent in commercial sex work is often missing and past history of STIs is also susceptible to recall bias. It is likely that a certain random misclassification may

\section{Key messages}

- HPV prevalence in migrant FSW is high (39\%), as is the proportion having had a termination of pregnancy (38\%) and an acute STI (11\%). HIV prevalence was $8 \%$ in FSW from sub-Saharan Africa and under $1 \%$ in the women from other geographical areas

- The decreasing HPV prevalence with increasing age was seen in migrant FSW irrespective of their geographical origin supporting the existence of acquired HPV immunity after HPV exposure

- The fact that no differences by geographical origin were observed for acute STls suggests that past exposure to HPV may be a determinant of current HPV epidemiology, in line with what is known of acquired immunity to HPV have taken place which could explain the lack of observed association.

The association between hormonal contraceptives and persistent HPV infection has been reported by a number of studies, ${ }^{10}{ }^{26-30}$ and long term hormonal contraceptive use has been recently suggested to be associated with cervical carcinoma in women infected by high risk HPV. ${ }^{27}$ This association has been found for both long term use as well as in those women who ever used hormonal contraceptives. ${ }^{29} 30$ In our study, data on duration of hormonal contraceptives were not available but since the effect was only found for those who did not report using barrier methods, it is likely that these women might also be at higher risk of multiple HPV exposures.

The majority of studies report smoking as a risk factor for HPV persistence and malignant transformation. ${ }^{8}{ }^{10}$ However, previous studies have found lower HPV infection rates in smokers. ${ }^{51}$ We have found a lower risk of HPV infection in the subgroups of women over 25 years of age who smoked, but whether this association is spurious or caused by uncontrolled confounding is not clear since no dose-response effect was found (data not shown) and data on duration of smoking were poor.

This study shows that migrant FSWs are a priority group for sexual health promotion as evidenced by their high prevalence of HPV infection, acute STIs, positive syphilis serology, and termination of pregnancies. It has also confirmed the previously described decreasing prevalence with age and highlighted differences by geographical origin that merit further research into the epidemiology and the natural history of HPV infection in highly exposed and marginalised groups.

\section{CONTRIBUTORS}

JdA, AG, MJB, and JdR initiated this project; JB, PC, CG, and JL were responsible for data collection and data entry; MO, AG, BM, LM were responsible for laboratory work; JdA, FB, CG, and JL were responsible for statistical analyses; JdA and FB wrote the first draft of the paper; all authors were involved in the study design and commented interim drafts; all authors have reviewed the final manuscript.

\section{Authors' affiliations}

J del Amo, C González, J Losana, F Bolumar, Department of Public Health. Miguel Hernández University, Alicante, Spain 
C González, J Losana, Department of Public Health, Rey Juan Carlos University, Madrid, Spain

P Clavo, J Ballesteros, B Menéndez, J del Romero, Centro Sanitario Sandoval, Madrid. Instituto Madrileño de Salud, Spain

L Muñoz, A García-Saiz, M Ortiz, National Centre of Microbiology, Instituto de Salud Carlos III, Madrid, Spain

M J Belza, Nacional Centre of Epidemiology. Instituto de Salud Carlos III, Madrid, Spain

This study was supported by funds provided by the Spanish Medical Research Fund (FIS), through grant C03/09.

\section{REFERENCES}

1 Ferenczy A, Franco E. Persistent human papillomavirus infection and cervical neoplasia. Lancet Oncol 2002;3:11-16.

2 Munoz N, Bosch FX, de Sanjose S, et al. Multicenter Cervical Cancer Study Group. Epidemiologic classification of human papillomavirus types associated with cervical cancer. N Engl J Med 2003;348:518-27.

3 Franco EL, Rohan TE, Villa LL. Epidemiologic evidence and human papillomavirus infection as a necessary cause of cervical cancer. J Nat Cancer Inst 1999;91:506-11.

4 Schlecht NF, Kulaga S, Robitaille J, et al. Persistent human papillomavirus infection as a predictor of cervical intraepithelial neoplasia. JAMA 2001;286:3106-14.

5 Ho GY, Bierman R, Beardsley L, et al. Natural history of cervicovaginal papillomavirus infection in young women. N Engl J Med 1998;338:423-8.

6 Touse A, de San José S, Cuorsaget $O$, et al. Prevalence of anti-human papailomavirus type 16,18,31, and 58 virus like particles in women in the general population and in prostitutes. J Clin Microbiol $2001 ; 39: 4344-8$.

7 Karlsson R, Jonsson M, Edlund K, et al. Lifetime number of partners as the only independent risk factor for human papillomavirus infection: a populationbased study. Sex Transm Dis 1995;22:119-27.

8 Moscicki AB, Hills N, Shiboski S, et al. Risks for incident human papillomavirus infection and low-grade squamous intraepithelial lesion development in young females. JAMA 2001;285:2995-3002.

9 Baay MF, Tjalma WA, Weyler J, et al. Human papillomavirus infection in the female population of Antwerp, Belgium: prevalence in healthy women, women with premalignant lesions and cervical cancer. Eur J Gynaecol Oncol 2001;22:204-8.

10 Winer RL, Lee SK, Hughes JP, et al. Genital human papillomavirus infection: incidence and risk factors in a cohort of female university students. Am J Epidemiol 2003;157:218-26.

11 Rezza G, Giuliani M, Serraino D, et al. Risk factors for cervical presence of human papillomavirus DNA among women at risk for HIV infection. DIANAIDS Collaborative Study Group. Epidemiol Infect 1998;121:173-7.

12 Sanjose S, Valls I, Paz Canadas M, et al. Human papillomavirus and human immunodeficiency virus infections as risk factors for cervix cancer in women prisoners. Med Clin (Barc) 2000;115:81-4.

13 Kjaer SK, Svare El, Worm AM, et al. Human papillomavirus infection in Danish female sex workers. Decreasing prevalence with age despite continuously high sexual activity. Sex Transm Dis 2000;27:438-45.
14 Juarez-Figueroa LA, Wheeler CM, Uribe-Salas FJ, et al. Human papillomavirus: a highly prevalent sexually transmitted disease agent among female sex workers from Mexico City. Sex Transm Dis 2001;28:125-30.

15 Ishi K, Suzuki F, Saito A, et al. Prevalence of human papillomavirus infection and its correlation with cervical lesions in commercial-sex workers in Japan. J Obstet Gynaecol Res 2000;26:253-7.

16 Chatterjee R, Mukhopadhyay D, Murmu N, et al. Prevalence of human papillomavirus infection among prostitutes in Calcutta. J Environ Pathol Toxicol Oncol 2001;20:113-17.

17 European Project AIDS and Mobility. East-West mobility in Europe: overcoming barriers to HIV prevention for mobile and migrant sex workers. Report of the European Seminar. Vienna, 7-10 June 2001 (www.aidsmobility.org/am5al.htm).

18 The EPI-VIH Study Group. HIV infection among people of foreign origin voluntarily tested in Spain. A comparison with national subjects. Sex Transm Infect 2002;78:250-4

19 Rodríguez MA, Ramón P, Rodrigo J, et al. The importance of migration on prostitution and HIV/AIDS in Spain in the last year. XIV International AIDS Conference. Barcelona, Spain, 7-12 July 2002. Abstract ThPeE7807.

20 Belza MJ, on behalf of the Spanish Group for the Unlinked Anonymous Survey of HIV sero-prevalence in STD patients. Prevalence of HIV, HTLV-I and HTLV-II among female sex workers in Spain, 2000-2001. Eur J Epidemiol 2005; (in press).

21 De Villiers EM, Wagner D, Schneider A, et al. Human papillomavirus infections in women with and without abnormal cervical cytology. Lancet 1987;2:703-6.

22 Burk RD, Kelly P, Feldman J, et al. Declining prevalence of cervicovaginal human papillomavirus infection with age is independent of other risk factors. Sex Transm Dis 1996;23:333-41.

23 Woodman CB, Collins S, Winter $\mathrm{H}$, et al. Natural history of cervical human papillomavirus infection in young women: a longitudinal cohort study. Lancet 2001;357:1831-6.

24 Molano M, Van den Brule A, Plummer M, et al. Determinants of clearance of human papillomavirus infections in Colombian women with normal cytology: a population-based, 5-year follow-up study. Am J Epidemiol 2003; 158:486-94.

25 Belza MJ, Clavo P, Ballesteros J, et al. The social and work situation, risk behaviour and sexually transmitted disease prevalence amongst female immigrant prostitutes in Madrid. Gac Sanit 2005;(in press).

26 Moreno V, Bosch FX, Munoz N, et al. Effect of oral contraceptives on risk of cervical cancer in women with human papillomavirus infection: the IARC multicentric case-control study. Lancet 2002;359:1085-92.

27 Madeleine MM, Daling JR, Schwartz SM, et al. Human papillomavirus and long-term oral contraceptive use increase the risk of adenocarcinoma in situ of the cervix- Cancer Epidemiol Biomarkers Prev 2001;10:171-7.

28 Green J, Berrington de Gonzalez A, Smith JS, et al. Human papillomavirus infection and use of oral contraceptives. Br J Cancer 2003;88:1713-20.

29 de Villiers EM. Relationship between steroid hormone contraceptives and HPV, cervical intraepithelial neoplasia and cervical carcinoma. Int J Cancer 2003; 103:705-8

30 Smith JS, Green J, Berrington de Gonzalez A, et al. Cervical cancer and use of hormonal contraceptives: a systematic review. Lancet 2003:361:1159-67.

31 Hildesheim A, Schiffman MH, Gravitt PE, et al. Persistence of type-specific human papillomavirusinfection among cytologically normal women. J Infect Dis 1994; 169:235-40. 